\title{
The occurrence and ecology of microbial chain elongation of carboxylates in soils
}

\author{
Sayalee Joshi $\mathbb{B}^{1} \cdot$ Aide Robles $\mathbb{1}^{1,2,3} \cdot$ Samuel Aguiar $\mathbb{D}^{2,4} \cdot$ Anca G. Delgado $\mathbb{1}^{1,2,3}$
}

Received: 13 July 2020 / Revised: 14 December 2020 / Accepted: 13 January 2021 / Published online: 8 February 2021

(c) The Author(s) 2021. This article is published with open access

\begin{abstract}
Chain elongation is a growth-dependent anaerobic metabolism that combines acetate and ethanol into butyrate, hexanoate, and octanoate. While the model microorganism for chain elongation, Clostridium kluyveri, was isolated from a saturated soil sample in the 1940s, chain elongation has remained unexplored in soil environments. During soil fermentative events, simple carboxylates and alcohols can transiently accumulate up to low $\mathrm{mM}$ concentrations, suggesting in situ possibility of microbial chain elongation. Here, we examined the occurrence and microbial ecology of chain elongation in four soil types in microcosms and enrichments amended with chain elongation substrates. All soils showed evidence of chain elongation activity with several days of incubation at high $(100 \mathrm{mM})$ and environmentally relevant $(2.5 \mathrm{mM})$ concentrations of acetate and ethanol. Three soils showed substantial activity in soil microcosms with high substrate concentrations, converting 58\% or more of the added carbon as acetate and ethanol to butyrate, butanol, and hexanoate. Semi-batch enrichment yielded hexanoate and octanoate as the most elongated products and microbial communities predominated by $C$. kluyveri and other Firmicutes genera not known to undergo chain elongation. Collectively, these results strongly suggest a niche for chain elongation in anaerobic soils that should not be overlooked in soil microbial ecology studies.
\end{abstract}

\section{Introduction}

Microbial chain elongation is an anaerobic metabolism in which microorganisms grow and get energy by combining carboxylates, such as acetate (C2), with more reduced compounds, such as ethanol (C2), producing longer-chain carboxylates (typically C4-C8) [1, 2]. A connection

These authors contributed equally: Sayalee Joshi, Aide Robles.

Supplementary information The online version contains supplementary material available at https://doi.org/10.1038/s41396021-00893-2.

Anca G. Delgado

anca.delgado@asu.edu

1 School of Sustainable Engineering and the Built Environment, Arizona State University, Tempe, AZ, USA

2 Biodesign Swette Center for Environmental Biotechnology, Arizona State University, Tempe, AZ, USA

3 Engineering Research Center for Bio-mediated and Bio-inspired Geotechnics (CBBG), Arizona State University, Tempe, AZ, USA

4 Department of Civil and Environmental Engineering, University of Illinois at Urbana-Champaign, Urbana, IL, USA between microbial chain elongation and soils was established more than 150 years ago. Béchamp [3] documented production of a high concentration of hexanoate (C6) in a bottle kept closed for months containing an aqueous ethanol solution with chalk (and soil microorganisms) collected from a dry riverbed. Work in the 1930s with freshwater and marine muds (including a canal mud from Delft, The Netherlands) later produced several isolates of a novel species, Clostridium kluyveri [1], the model microorganism for chain elongation. For C. kluyveri, microbial chain elongation of carboxylates is its only growth-dependent metabolism $[1,4,5]$. When fed with acetate and ethanol, $C$. kluyveri produces butyrate (C4), hexanoate (or caproate), and $\mathrm{H}_{2}$ as metabolites [6]; propionate (C3) and ethanol are converted to the odd-numbered carboxylates, valerate (C5), and heptanoate (C7) [7].

Carboxylate chain elongation by $C$. kluyveri is achieved via reverse $\beta$-oxidation [8], resulting in a two-C elongation per cycle (Eqs. 1-2). Running $\beta$-oxidation in the reserve direction is thermodynamically favorable [9] but requires certain environmental conditions, such as the presence of energy-rich, reduced compounds like ethanol, and a high enough $\mathrm{H}_{2}$ partial pressure $\left(10^{-1} \mathrm{kPa}\right)$ to prevent (forward) $\beta$-oxidation [10]. In chain elongation, the carboxylate is the 
electron acceptor and the more reduced compound (e.g., ethanol) is the electron donor [2]. As seen in Eqs. 1 and 2, the elongations reactions are thermodynamically favorable, yielding a similar Gibbs-free energy [11] per elongation step:

$$
\begin{aligned}
& \mathrm{CH}_{3} \mathrm{COO}^{-}+\mathrm{CH}_{3} \mathrm{CH}_{2} \mathrm{OH} \rightarrow \mathrm{CH}_{3} \mathrm{CH}_{2} \mathrm{CH}_{2} \mathrm{COO}^{-}+\mathrm{H}_{2} \mathrm{O} ; \Delta \mathrm{G}^{\circ \prime} \\
& \text { Acetate Ethanol Butyrate } \\
& =-38.8 \frac{\mathrm{kJ}}{\text { reaction }}
\end{aligned}
$$

$$
\begin{aligned}
& \mathrm{CH}_{3} \mathrm{CH}_{2} \mathrm{CH}_{2} \mathrm{COO}^{-}+\mathrm{CH}_{3} \mathrm{CH}_{2} \mathrm{OH} \rightarrow \mathrm{CH}_{3} \mathrm{CH}_{2} \mathrm{CH}_{2} \mathrm{CH}_{2} \mathrm{CH}_{2} \mathrm{COO}^{-} \\
& \text {Butyrate Ethanol Hexanoate } \\
& +\mathrm{H}_{2} \mathrm{O} ; \Delta \mathrm{G}^{\circ \prime}=-38.7 \frac{\mathrm{kJ}}{\text { reaction }}
\end{aligned}
$$

$\mathrm{H}_{2}$ production, shown in Eq. 3, is a result of partial ethanol oxidation by ferredoxin-dependent hydrogenases and yields ATP and NADH for the microorganisms $[8,10]$ :

$$
\underset{\text { Ethanol }}{\mathrm{CH}_{3} \mathrm{CH}_{2} \mathrm{OH}}+\mathrm{H}_{2} \mathrm{O} \rightarrow \underset{\text { Acetate }}{\mathrm{CH}_{3} \mathrm{COO}^{-}+\mathrm{H}^{+}+2 \mathrm{H}_{2} ; \Delta \mathrm{G}^{\circ \prime}}=+9.7 \frac{\mathrm{kJ}}{\text { reaction }}
$$

Given that Eq. 3 is endergonic, it must be coupled with the reactions shown in Eq. 1 and/or 2 for the net reaction to be thermodynamically favorable.

Since the isolation of C. kluyveri, work on microbial chain elongation has developed based on two trajectories. Early research focused on microbiological characterizations and resolving the biochemical pathways involved in producing and oxidizing fatty acids in C. kluyveri [7, 12-14]. A more recent focus exploits chain elongation by microbial communities containing $C$. kluyveri or other members of Firmicutes for production of biochemicals and biofuels $[15,16]$. The latter has gained substantial momentum in engineering bio- $[17,18]$ and bioelectrochemical-reactors $[19,20]$ for conversion of various waste streams (i.e., food waste, municipal solid waste, agriculture waste, and syngas) into hexanoate and octanoate (C8), high-value mediumchain carboxylates. To that end, samples from natural and engineered environments have been used as bioreactor inocula and sources of chain-elongating microorganisms, including anaerobic digestor sludges, process wastewaters, rumen contents, and herbivore feces $[18,21]$.

Like municipal or agriculture waste streams, anaerobic soils and sediments often contain an abundance of biodegradable organic compounds. Under anaerobic conditions and with limited availability of electron acceptors, biodegradation of complex organic compounds is described by the anaerobic food web, a cascade of hydrolytic, fermentative, and methanogenic reactions involving a complex microbial community [22]. Transient fermentative accumulation of short-chain carboxylates and simple alcohols has been detected in anaerobic soils up to mM concentrations [23-25]. In top soils, short-chain carboxylates are also exudates from the roots of plants [26]. Given that microorganisms capable of chain elongation utilize carboxylates and simple alcohols as substrates, we hypothesized that microbial chain elongation could be a likely metabolic pathway in anaerobic soils. While sporadic accounts place C. kluyveri as part of the natural microbial communities of freshwater, brackish, or marine sediments [1, 5], the function and metabolism of $C$. kluyveri in its soil or sediment cradle remain unexplored. Furthermore, chain elongation is not considered in models for organic compounds biodegradation like the anaerobic food web [22].

In this study, we utilized four soil types collected from various depths with diverse biogeochemical characteristics in microcosms and enrichments in an effort to understand the occurrence of microbial chain elongation as a growthsupporting metabolism and its microbial ecology. We present evidence for microbial chain elongation as a substantial, but not previously considered, soil metabolism in microcosms and subsequent soil enrichments with implications for organic carbon dynamics and microbial ecology in anaerobic soil environments.

\section{Materials and methods}

\section{Soil microcosms and conditions tested}

Four soils were used in this study and are described in Table 1. The soils are referred to according to their city sampling location: Tempe, Bozeman, Lucas, and Goodyear. Tempe and Bozeman soils were collected using a hand trowel from a depth of $0.2-0.4 \mathrm{~m}$ below the ground surface. Lucas soil was excavated from a depth of $1.5 \mathrm{~m}$. Goodyear soil was acquired through drill coring from a depth of $25-52 \mathrm{~m}$ below ground surface [27]. Equal parts of $\sim 0.1 \mathrm{~kg}$ of soil cores from $25-52 \mathrm{~m}$ depths were homogenized to create composite Goodyear soil. All soils were thoroughly mixed in an anaerobic glove chamber before using them in microcosms.

Duplicate soil microcosms were established in the anaerobic chamber in $250 \mathrm{~mL}$ glass serum bottles [28] according to Table 2. Microcosms consisted of $25 \mathrm{~g}$ of soil and $75 \mathrm{~mL}$ of reduced anaerobic mineral medium (1:3 soil to liquid ratio) as described previously [29]. The medium was buffered with $12.5 \mathrm{mM}$ phosphate and had an initial $\mathrm{pH}$ of 7.5. $10 \mathrm{mM}$ sodium 2-bromoethanesulfonate (BES), a methanogenesis inhibitor, was added at time zero in all microcosms. The substrate(s) concentrations and conditions tested are shown in Table 2. The initial concentration of $\mathrm{H}_{2}$ gas was $90 \mathrm{mM}$ (nominal concentration). All microcosms 
Table 1 Description and characteristics of study soils.

\begin{tabular}{|c|c|c|c|c|c|c|}
\hline Soil ID & Location & Description & Soil type & $\mathrm{pH}$ & $\begin{array}{l}\text { Conductivity } \\
\left(\mu \mathrm{S} \mathrm{cm}^{-1}\right)\end{array}$ & $\begin{array}{l}\text { Organic carbon } \\
\left(\mathrm{mg} \mathrm{g}^{-1} \text { soil }\right)\end{array}$ \\
\hline Tempe & $\begin{array}{l}\text { Tempe, } \\
\text { Arizona, USA }\end{array}$ & $\begin{array}{l}\text { Top soil from an area covered } \\
\text { with vegetation from } 0.2-0.3 \mathrm{~m} \\
\text { below ground surface }\end{array}$ & Silty clay loam & $7.8 \pm 0.3$ & $170 \pm 30$ & $37 \pm 3$ \\
\hline Bozeman & $\begin{array}{l}\text { Bozeman, } \\
\text { Montana, USA }\end{array}$ & $\begin{array}{l}\text { Top soil from an area covered } \\
\text { with vegetation from } 0.2 \text { to } \\
0.4 \mathrm{~m} \text { below ground surface }\end{array}$ & Silt loam & $7.7 \pm 0.2$ & $180 \pm 20$ & $140 \pm 7$ \\
\hline Lucas & $\begin{array}{l}\text { Lucas, } \\
\text { Texas, USA }\end{array}$ & $\begin{array}{l}\text { Deep soil from } 1.5 \mathrm{~m} \text { below } \\
\text { ground surface }\end{array}$ & Clay & $5.7 \pm 0.5$ & $80 \pm 10$ & $20 \pm 3$ \\
\hline Goodyear & $\begin{array}{l}\text { Goodyear, } \\
\text { Arizona, USA }\end{array}$ & $\begin{array}{l}\text { Deep soil from } 25 \text { to } 52 \mathrm{~m} \\
\text { below ground surface }\end{array}$ & $\begin{array}{l}\text { Mix of loamy sand, sandy } \\
\text { clay, and sand cores }\end{array}$ & $7.6 \pm 0.4$ & $180 \pm 10$ & $5.7 \pm 0.3$ \\
\hline
\end{tabular}

The data are averages with standard deviation of triplicate soil samples.

Table 2 Experimental conditions tested in microcosms and enrichments with Tempe, Bozeman, Lucas, and Goodyear soils.

\begin{tabular}{llllllll}
\hline Microcosm condition & Soil used & \multicolumn{3}{c}{$\begin{array}{l}\text { Semi-batch cycle \# } \\
\text { incubation (days) }\end{array}$} \\
\cline { 3 - 8 } & & 1 & 2 & 3 & 4 & 5 \\
\hline $100 \mathrm{mM}$ acetate $+100 \mathrm{mM}$ & All & 14 & 8 & 6 & $9^{\mathrm{c}}$ & $7^{\mathrm{c}}$ \\
ethanol $^{\mathrm{a} b}$ & & & & & & \\
$100 \mathrm{mM}$ ethanol & & & & & & & \\
$100 \mathrm{mM}$ acetate $+\mathrm{H}_{2}{ }^{\mathrm{a}}$ & All & Lucas & 14 & 6 & 43 & $7^{\mathrm{c}}$ & - \\
$100 \mathrm{mM}$ ethanol $+\mathrm{H}_{2}{ }^{\mathrm{a}}$ & Lucas & 14 & 8 & 6 & $16^{\mathrm{c}}$ & - \\
$140 \mathrm{mM}$ acetate & All & $14^{\mathrm{c}}$ & - & - & - & - \\
$10 \mathrm{mM}$ acetate $+10 \mathrm{mM}$ & Tempe, & 15 & - & - & - & - \\
ethanol & Lucas & & & & & \\
$2.5 \mathrm{mM}$ acetate $+2.5 \mathrm{mM}$ & Tempe, & 15 & - & - & - & - \\
ethanol & Lucas & & & & & \\
No substrates & All & $14^{\mathrm{c}}$ & - & - & - & - \\
\hline
\end{tabular}

${ }^{\mathrm{a}}$ Condition selected for enrichment in semi-batch cycles. A semi-batch cycle consisted of removing $25 \mathrm{~mL}$ microcosm slurry (one third of microcosm liquid) and replacing with $25 \mathrm{~mL}$ mineral medium containing acetate and/or ethanol at $\sim 100 \mathrm{mM}$.

${ }^{b}$ Five cycles were completed for Tempe, Bozeman, and Lucas soils and four cycles were completed for Goodyear soil.

${ }^{\mathrm{c}}$ Timepoint sampled for high-throughput DNA sequencing.

were incubated in the dark at $30^{\circ} \mathrm{C}$ and agitated at $125 \mathrm{rpm}$ on a platform shaker.

\section{Enrichments from microcosms in semi-batch cycles}

The microcosms with $100 \mathrm{mM}$ acetate $+100 \mathrm{mM}$ ethanol, $100 \mathrm{mM}$ ethanol, $100 \mathrm{mM}$ acetate $+\mathrm{H}_{2}$, and $100 \mathrm{mM}$ ethanol $+\mathrm{H}_{2}$ (Table 2) were subjected to an enrichment process in semi-batch cycles after the initial 14-day incubation (end of cycle 1). A semi-batch cycle consisted of removing $25 \mathrm{~mL}$ of microcosm slurry (one third of liquid) and replacing with $25 \mathrm{~mL}$ of fresh anaerobic medium with the corresponding substrate(s) at $\sim 100 \mathrm{mM}$ (Table 2). The concentration of $\mathrm{H}_{2}$ in the headspace was maintained at 90 $\mathrm{mM}$ (nominal concentration) by adding ultra-high purity $\mathrm{H}_{2}$ gas with a gastight syringe. BES was not added during the enrichment process. The enrichments were incubated in the dark at $30^{\circ} \mathrm{C}$ according to the schedule from Table 2 and agitated at $125 \mathrm{rpm}$ on a platform shaker.

\section{Chemical analytical methods}

Initial soil $\mathrm{pH}$ and conductivity were measured in soil slurries (1:1 soil to DI water by weight) using an Oakton MultiParameter PCSTestr 35 probe (Vernon Hills, IL, USA). The probe was calibrated according to the manufacturer's instructions using Oakton calibration standards. $\mathrm{pH}$ at time zero or end of a semi-batch cycle was measured directly on the microcosm slurry using a Sartorius $\mathrm{pH}$ bench top meter (Thermo Scientific, Waltham, MA, USA). The initial concentration of organic carbon in the soils was measured using a Shimadzu TOC-V SPH Total Carbon Analyzer (Columbia, MD, USA) with a solid state module (SSM-5000A) [30]. The calibration was performed using glucose (Acros Organics, NJ, USA) in a range of $0.5-25 \mathrm{mg} \mathrm{C}$. The method minimum detection limit was $0.3 \mathrm{mg} \mathrm{C} \mathrm{kg}^{-1}$ soil.

The concentrations of $\mathrm{C} 2-\mathrm{C} 8$ carboxylates, ethanol, butanol, and hexanol in microcosm liquid were analyzed using a high-performance liquid chromatograph (HPLC, Shimadzu LC-20AT) with a photodiode array detector at $210 \mathrm{~nm}$ and a refractive index detector [31-33]. The HPLC was equipped with an Aminex HPX-87H column (Bio-Rad, Hercules, CA, USA). The eluent was $2.5 \mathrm{mM} \mathrm{H}_{2} \mathrm{SO}_{4}$ at $0.6 \mathrm{~mL} \mathrm{~min}^{-1}$ for $30 \mathrm{~min}$ followed by $0.8 \mathrm{~mL} \mathrm{~min}^{-1}$ for another $90 \mathrm{~min}$. The oven temperature was kept constant at $65^{\circ} \mathrm{C}$. The minimum detection limit for carboxylates was $\leq 0.04 \mathrm{mM}$ and $\leq 0.1 \mathrm{mM}$ for alcohols. The concentrations of substrates and metabolites in figures are shown in $\mathrm{mM} \mathrm{C}$ to aid in following the carbon balance.

$\mathrm{H}_{2}$ and methane concentrations were analyzed from gas headspace samples using a gas chromatograph (GC, 
Shimadzu GC 2010) with a thermal conductivity detector (TCD) and a Carboxen 1010 PLOT column (Supelco, Bellefonte, PA, USA) [34]. The carrier gas was ultra-high purity argon with a constant pressure and flow rate of $42.3 \mathrm{kPa}$ and $10 \mathrm{~mL} \mathrm{~min}^{-1}$, respectively. The temperature of the injector was $150^{\circ} \mathrm{C}$, the TCD temperature was $180^{\circ} \mathrm{C}$, and the current was set at $41 \mathrm{~mA}$. The column temperature was initially held to $80^{\circ} \mathrm{C}$ for $3 \mathrm{~min}$, ramped to $160^{\circ} \mathrm{C}$ at $50{ }^{\circ} \mathrm{C} \mathrm{min}^{-1}$ and held for $1.5 \mathrm{~min}$. The minimum detection limits for $\mathrm{H}_{2}$ and methane were $0.02 \mathrm{mM}$ and $0.03 \mathrm{mM}$ (gas concentrations), respectively. The total gas volume in the headspace of the microcosms was measured with a 50-mL frictionless syringe (Perfektum $\mathrm{R}$ matched numbered hypodermic syringes, Sigma Aldrich, St. Louis, MO, USA).

\section{DNA extraction and high-throughput DNA sequencing}

Pellets for DNA extraction were obtained from $1.5 \mathrm{~mL}$ of microcosm soil slurry on day zero and at the end of incubation as noted in Table 2. Genomic DNA was extracted using a Power Soil DNA Isolation Kit (MO BIO Laboratories, Inc., Carlsbad, CA, USA). The DNA concentrations and purity were determined by measuring absorbance at wavelengths of $260 \mathrm{~nm}$ and $280 \mathrm{~nm}$ with a NanoDrop spectrophotometer (Rockland, DE, USA). Microbial community amplicon sequencing was performed using a MiSeq instrument (Illumina, Inc., San Diego, CA, USA) from the Center for Fundamental and Applied Microbiomics at the ASU KED Genomics Core Facility, Arizona State University, Tempe, AZ, USA. The primers were $515 \mathrm{~F}$ ( $5^{\prime}-$ GTGCCAGCMGCCGCGGTAA-3') and 806R (5'-GGAC TACHVGGGTWTCTAAT- $3^{\prime}$ ) [35] for the V4 hypervariable region of the $16 \mathrm{~S}$ rRNA gene which captures Bacteria and Archaea [36]. Forward and reverse sequences $(2 \times 150$ mode) were first paired (overlap $\geq 45$ base-pairs) using PANDASeq [37]. The paired reads (average length 250 base pairs) were processed using the bioinformatics software Quantitative Insights into Microbial Ecology (QIIME 2, v. 2020.8) pipeline [38]. DADA2 was employed for detecting and correcting sequence data as a means for quality control and truncating each sequence at 151 base pairs to maintain a quality score of 25 or better. Taxonomy was assigned to amplicon sequence variants (ASVs) [39] using a pre-trained Naive Bayes classifier referencing SILVA database (v. 138) with a 99\% identity threshold from $515 \mathrm{~F} / 806 \mathrm{R}$ region of sequences and the q2-featureclassifier plug in [40-42]. BLAST + consensus taxonomy classifier plug in was used to query the sequences against the National Center for Biotechnology (NCBI) database [43]. The raw sequence data were uploaded to NCBI and are available under project number PRJNA552606.

\section{Carbon and electron balances}

Carbon and electron balances were performed for selected microcosm conditions to determine distribution of $\mathrm{C}$ and electrons from chain elongation substrates consumed to metabolites identified. The number of $\mathrm{Cs}$ per mol of compound are as follows: acetate, 2; ethanol, 2; butyrate, 4; butanol, 4; hexanoate, 6; hexanol, 6; and octanoate, 8 . For electron balances, mmol of added substrates and metabolites were converted to millielectron equivalents (me $\mathrm{e}^{-}$equiv.). The number of $\mathrm{me}^{-}$equiv. for each compound are as follows [11]: acetate, 8 ; ethanol, 12; butyrate, 20; butanol, 24; hexanoate, 32; hexanol, 36; and octanoate, 44. The C/electron balances were calculated by dividing mmol C or me ${ }^{-}$equiv. of each metabolite at the end of a cycle by the total mmol $\mathrm{C}$ or $\mathrm{me}^{-}$equiv. consumed from added substrate(s).

\section{Results and discussion}

\section{Substantial microbial chain elongation activity in soils at high and environmentally relevant substrate concentrations}

The soils examined were chosen to capture different soil types (various proportions of silt, clay, and sand) with varying characteristics, including $\mathrm{pH}$ and endogenous organic carbon concentration (Table 1). Based on the sample collection depth, study soils were also expected to showcase varying levels of microbial activity (e.g., microbial activity typically decreases as a function of soil depth). All soils showed evidence of microbial chain elongation activity in at least one microcosm condition starting in cycle 1 (Figs. 1, 2-3, and S1 and S2, cycle 1). Microbial chain elongation of acetate and ethanol was the major metabolism occurring in Tempe, Bozeman, and Lucas soils, as evident by the high concentration of the metabolites. $58-117 \%$ of the consumed mmol C and $53-104 \%$ of the consumed $\mathrm{me}^{-}$ equiv. from substrates were recovered as $\mathrm{C} 4-\mathrm{C} 6$ carboxylates and alcohols by the end of cycle 1 (Table S1). We observed transient acetate accumulation as a metabolite in the ethanol microcosms (Fig. 1 and S2 (cycle 1)), possibly from ethanol oxidation (Eq. 2), which then initiated chain elongation to butyrate. Chain elongation activity was lowest but significant nonetheless in Goodyear soil (Table S1) where $0.78 \pm 0.08 \mathrm{mMC} n$-butyrate was produced during cycle 1 (Fig. 2). Methane was absent in all conditions.

In control microcosms without added substrates, acetate was the only metabolite detected on day 14 of incubation (Fig. S3) at concentrations similar to those recorded in anaerobic incubations of forest [44, 45], bog [46], or paddy soils [47]. The absence of $\mathrm{C} 4$ or greater metabolites 


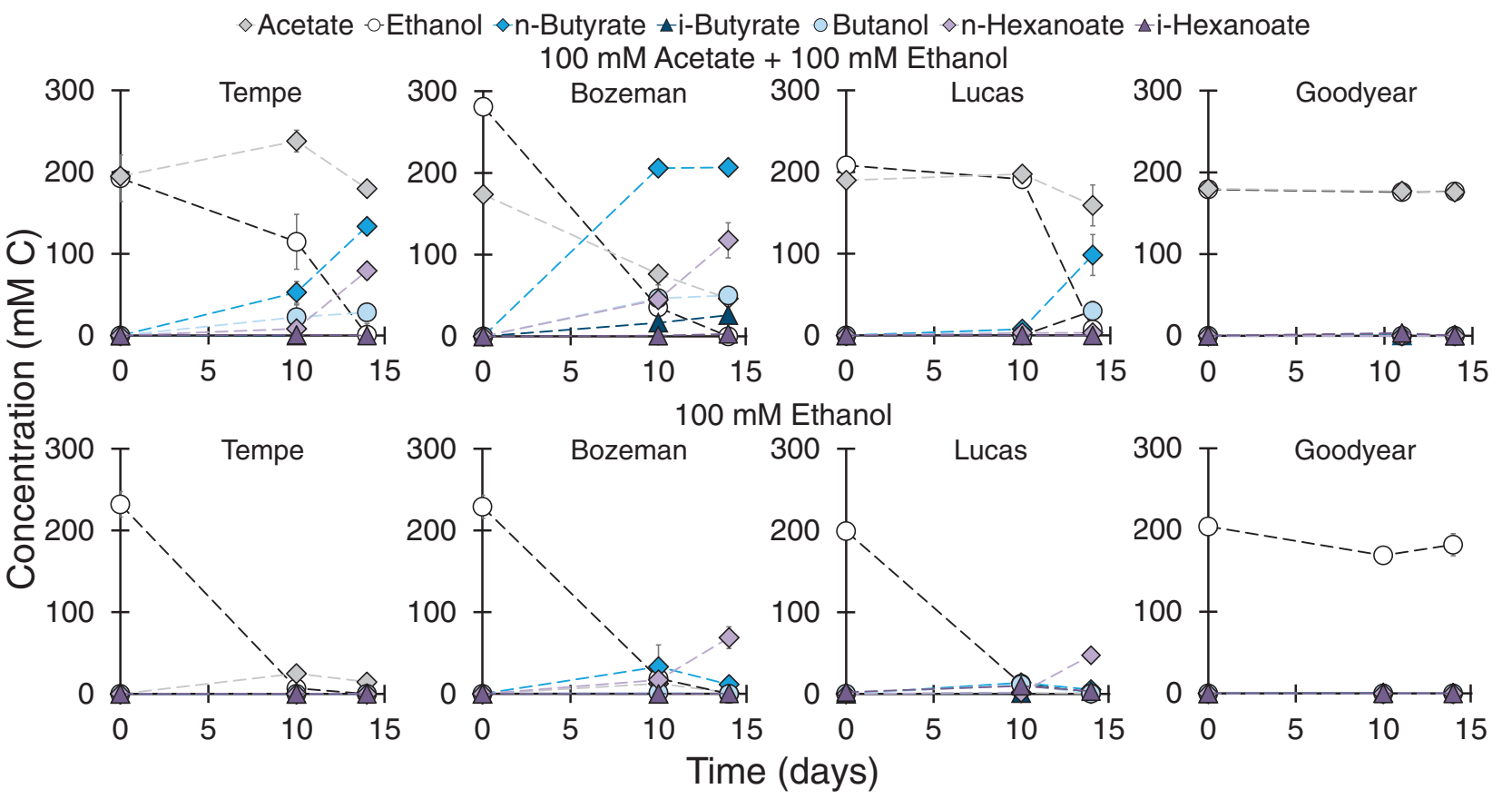

Fig. 1 Microbial chain elongation activity in microcosms ( $25 \mathrm{~g}$ soil and $75 \mathrm{~mL}$ medium) with Tempe, Bozeman, Lucas, and Goodyear

mM ethanol. The data are averages with standard deviation of soils amended with $100 \mathrm{mM}$ acetate and $100 \mathrm{mM}$ ethanol or 100

duplicate microcosms.

Fig. 2 Metabolites during microbial chain elongation in soils initially fed with $100 \mathrm{mM}$ acetate and $100 \mathrm{mM}$ ethanol and subjected to semi-batch enrichment. A semi-batch cycle consisted of removing one third of microcosm liquid $(25 \mathrm{~mL})$ and replacing with $25 \mathrm{~mL}$ medium containing $100 \mathrm{mM}$ acetate and $100 \mathrm{mM}$ ethanol. The incubation time for each cycle (between $6-14$ days) is shown in Table 2. The plotted carboxylates and alcohols are final measured metabolite concentrations at the end of each cycle before liquid was removed and medium with substrates was readded. The data are averages with standard deviation of duplicate microcosms.

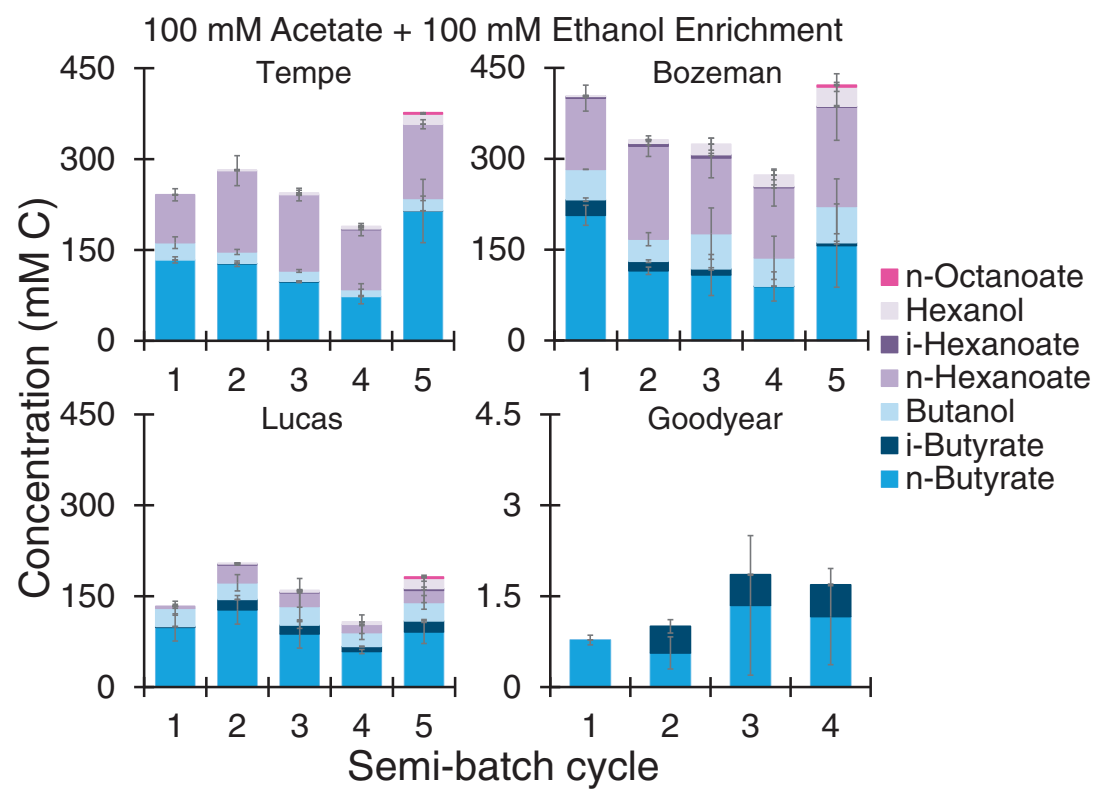

without added substrates and the C/electron balances (Table S1) corroborate the formation of butyrate, butanol, hexanoate, and hexanol from microbial chain elongation of added acetate and/or ethanol rather than processes involving the fermentation or oxidation of natural organic carbon of the soils. The soil microcosms with $140 \mathrm{mM}$ acetate (no ethanol or $\mathrm{H}_{2}$ ) did not produce butyrate or hexanoate within 2 weeks of incubation (Fig. S3). These data substantiate that a more-reduced, organic C-containing compound must be present to serve as the electron donor for chain elongation activity to occur.

We wondered if utilization of acetate and ethanol for microbial chain elongation is possible at lower, environmentally relevant concentrations observed during transient fermentative accumulation in soils. Figure 4 documents that the combination of acetate and ethanol at 
Fig. 3 Metabolites during microbial chain elongation in soils initially fed with $100 \mathrm{mM}$ ethanol and subjected to semibatch enrichment. A semibatch cycle consisted of removing one third of microcosm liquid $(25 \mathrm{~mL})$ and replacing with $25 \mathrm{~mL}$ medium containing $100 \mathrm{mM}$ ethanol. The incubation time for each cycle (between 6-43 days) is shown in Table 2. The plotted carboxylates and alcohols are final measured metabolite concentrations at the end of each cycle before liquid was removed and medium with substrates was readded. The data are averages with standard deviation of duplicate microcosms.

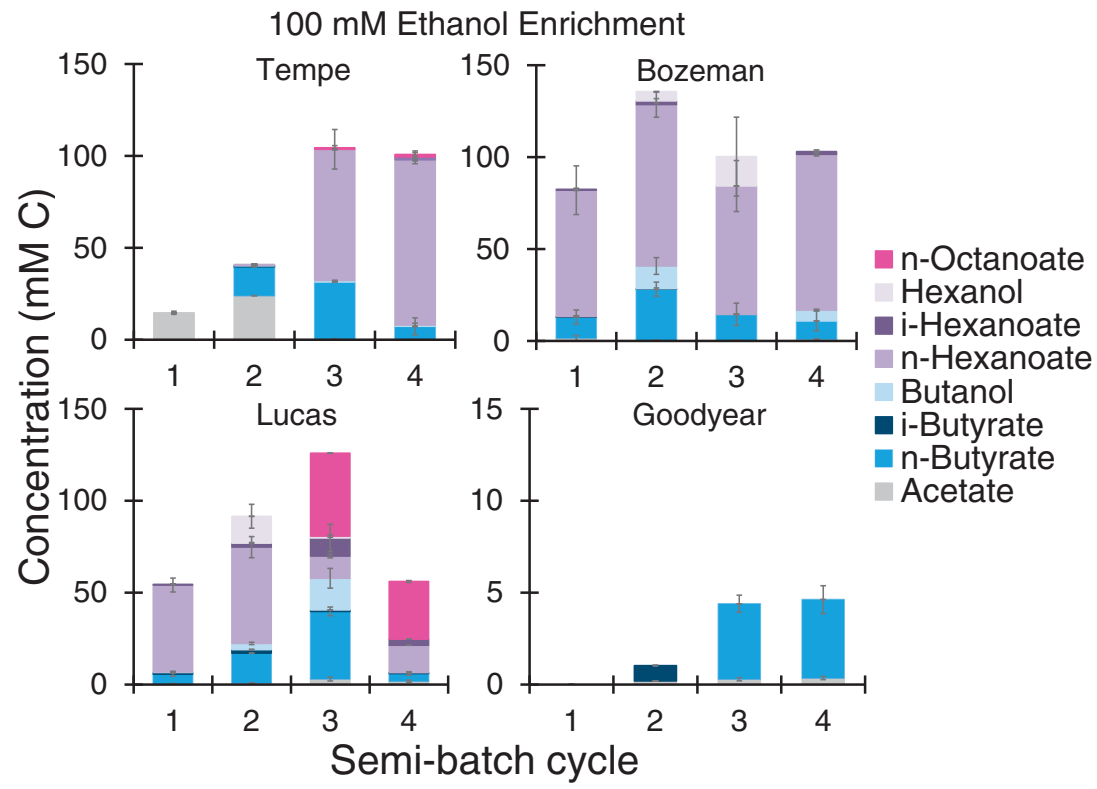

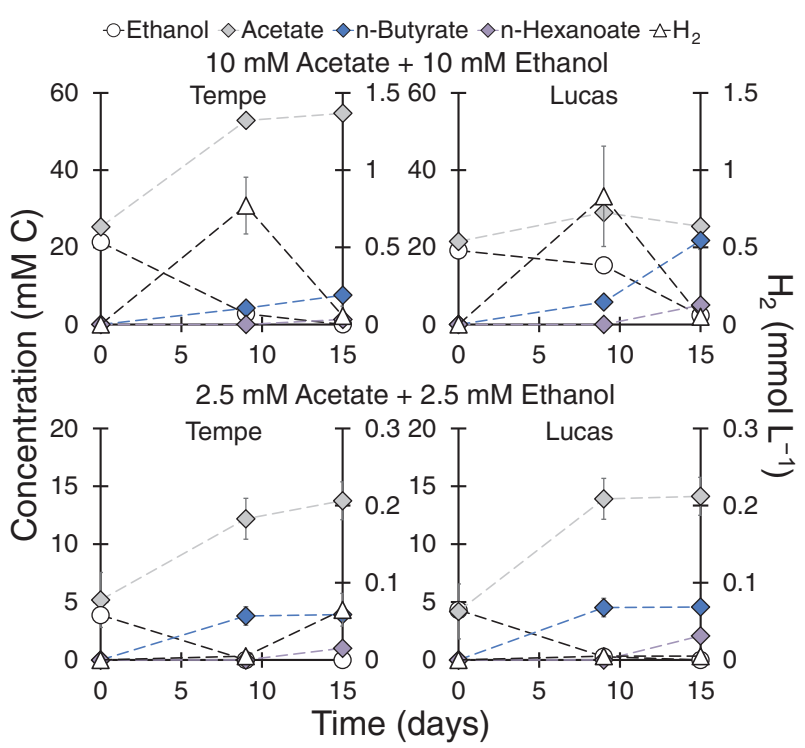

Fig. 4 Microbial chain elongation of acetate and ethanol at lower substrate concentrations in Tempe and Lucas soil microcosms ( $25 \mathrm{~g}$ soil and $75 \mathrm{~mL}$ medium). The data are averages with standard deviation of duplicate microcosms.

$10 \mathrm{mM}$ each or $2.5 \mathrm{mM}$ each triggers the use of acetate as a soil electron acceptor in chain elongation. Tempe and Lucas soils completely consumed the added ethanol, producing butyrate and ultimately hexanoate (Fig. 4). The microcosms in Fig. 4 showed a net accumulation of acetate higher than expected from ethanol oxidation (Eq. 3) or than observed in the control microcosms without added substrates (Fig. S3). A feasible pathway for acetate production in these microcosms is homoacetogenesis using $\mathrm{HCO}_{3}{ }^{-} / \mathrm{CO}_{2}$ as the electron acceptor $[44,48]$, which was conceivably activated by $\mathrm{H}_{2}$ released from chain elongation (Fig. 4).

\section{Subsequent enrichment augments microbial chain elongation to longer carboxylates}

Microbial chain elongation activity continued in all soils in subsequent enrichment in semi-batch cycles (Figs. 2 and 3, and S1 and S2). In the acetate + ethanol soil enrichments, butyrate and hexanoate were the main metabolites produced, while $n$-octanoate $(1.69 \pm 0.01-2.94 \pm 1.05 \mathrm{mMC})$ was also detected in Tempe and Bozeman soils during cycle 5 (Figs. 2 and S4). In Tempe, Bozeman, and Lucas soil enrichments, addition of ethanol (without acetate) augmented the production of more elongated carboxylates after two or three semi-batch cycles (Figs. 3 and S2). In Lucas soil, $5.66 \pm 0.01 \mathrm{mM} n$-octanoate $(45 \mathrm{mM} \mathrm{C}$ ) was quantified by the end of cycle 3 when incubation was extended to 43 days (Fig. 3) and the $\mathrm{pH}$ was between 6.34 and 6.39 (Fig. S5). Accumulation of $n$-octanoate in Lucas soil enrichment during cycle 3 was possible as the undissociated $n$-octanoic acid concentration $(0.18 \mathrm{mM})$ was three times less than the inhibitory concentration reported by Kucek et al. (0.63 mM undissociated $n$-octanoic acid) [49]. While hexanoate can be produced during acidogenic fermentation of complex biomass [15], octanoate is neither such metabolite nor a typical compound measured in soils. Production of octanoate is possible by diverting precursors of phospholipid biosynthesis but requires genetic engineering of microbial host strains [50]. Octanoate, however, is a metabolite of acetate and ethanol chain elongation. Its production was first documented in 2011 using a C. kluyvericontaining mixed culture enriched from a bioreactor treating brewery wastewater [15]. It has since been observed in other chain elongation works [49, 51-53]. Two factors contributed to conversion to longer metabolites in the 
ethanol soil enrichments (Fig. 3, Tempe, Bozeman, and Lucas soils). A first is the high concentration of the electron donor, ethanol, that facilitates from an energy stand point the use C2-C6 carboxylates as electron acceptors [15]. A second is the stoichiometric ratio of ethanol to acetate, which was higher in the microcosms with ethanol (Fig. 3, $\geq 9$ mol ethanol: $1 \mathrm{~mol}$ acetate) compared to those in the microcosms with acetate and ethanol (Figs. 2, 1 mol ethanol: 1 mol acetate). To that extent, a number of studies showed that higher ethanol:acetate mol ratios favor elongation to hexanoate or longer carboxylates whereas lower ethanol:acetate ratios mainly stall at butyrate $[54,55]$.

In Lucas soil microcosms with acetate $+\mathrm{H}_{2}$, ethanol production was recorded (Fig. S1), likely via acetate reduction with $\mathrm{H}_{2}$ (Eq. 3 in reverse, $\Delta \mathrm{G}^{\prime \prime}=-9.7 \frac{\mathrm{kJ}}{\text { reaction }}$ ). These data allude to a requirement for an organic electron donor to initiate chain elongation of acetate to butyrate. In chain elongation, ethanol is the source for deriving the acetyl-CoA that elongates the carboxylate during a reverse $\beta$-oxidation cycle [56] and it is considered the most efficient reduced substrate for synthesis of butyrate and hexanoate in C. kluyveri [35]. Among enrichment conditions, concentrations of C4-C6 metabolites were lowest in the acetate $+\mathrm{H}_{2}$ enrichment for Lucas soil (Fig. S1). Conversion of acetate and $\mathrm{H}_{2}$ to ethanol (Eq. 3 in reverse) is typically characterized by sluggish kinetics [15], which likely limited the extent of butyrate and hexanoate production during the incubation time frame of the cycles (6-16 days). Butyrate production from acetate reduction with $\mathrm{H}_{2}$ is not a likely pathway in the microcosms and enrichments, as condensing two acetyl-CoA molecules is a highly endergonic reaction [9].

We used the time-course data from cycle 5 (shown in Fig. S4 from day 1 to 7) to determine the stoichiometry involved in chain elongation of acetate and ethanol by soil microorganisms after enrichment. To simplify the stoichiometries, we normalized all carboxylate and alcohol metabolites to butyrate mol $\mathrm{C}$ equivalents (e.g., $1 \mathrm{~mol}$ butanol $=1 \mathrm{~mol}$ butyrate, $1 \mathrm{~mol}$ hexanoate $/$ hexanol $=1.5$ mol butyrate, and $1 \mathrm{~mol}$ octanoate $=2 \mathrm{~mol}$ butyrate). We determined that the microbial communities from Tempe and Lucas soils were following the approximate stoichiometry from Eq. 4, while Bozeman soil stoichiometry was more similar to Eq. 5:

$$
\begin{aligned}
5 \mathrm{CH}_{3} \mathrm{CH}_{2} \mathrm{OH}+3 \mathrm{CH}_{3} \mathrm{COO}^{-} \rightarrow & 4 \mathrm{CH}_{3} \mathrm{CH}_{2} \mathrm{CH}_{2} \mathrm{COO}^{-} \\
& +\mathrm{H}^{+}+2 \mathrm{H}_{2}+3 \mathrm{H}_{2} \mathrm{O} \\
& \\
5 \mathrm{CH}_{3} \mathrm{CH}_{2} \mathrm{OH}+2 \mathrm{CH}_{3} \mathrm{COO}^{-} \rightarrow & 3.5 \mathrm{CH}_{3} \mathrm{CH}_{2} \mathrm{CH}_{2} \mathrm{COO}^{-} \\
+ & +1.5 \mathrm{H}^{+}+2 \mathrm{H}_{2}+2 \mathrm{H}_{2} \mathrm{O}
\end{aligned}
$$

The stoichiometries from our soil enrichments support previously proposed pathways requiring a ratio of $1 \mathrm{~mol}$ ethanol to $0.6 \mathrm{~mol}$ acetate consumed for every $0.8 \mathrm{~mol}$ butyrate produced [2].

\section{The prevalence and diversity of Firmicutes in chain- elongating soil enrichments}

The initial microbial ecology at the phylum level in soils (at time zero) and the community composition in response to chain elongation enrichment (end of cycles 4 or 5) are presented in Fig. 5. Tempe and Bozeman soils sampled closest to ground surface $(0.2-0.4 \mathrm{~m})$ had an initial, similar community structure, abundant in sequences most similar to Proteobacteria, Bacteroidetes, and Firmicutes (Fig. 5) and consistent with the typical phylum distribution in top soils from various geographical regions [57, 58]. In Lucas soil, the initial microbial community was dominated by Actinobacteria, Chloroflexi, and Verrucomicrobia (Fig. 5). The overwhelming majority of sequences in Goodyear soil belonged to Proteobacteria (Fig. 5). The relative abundance of the dominant phyla in Lucas and Goodyear likely reflects some of the key soil characteristics (Table 1), including deeper depth of sampling, high-clay content and low $\mathrm{pH}$ (soil L), and lower organic carbon content.

Knowledge on the microbial ecology involved in chain elongation has emerged only recently and stems exclusively from biotechnology-focused studies. The enrichment of Gram-positive, spore-forming Firmicutes has been consistently documented in chain-elongation laboratory batch cultures and bioreactors fed with defined simple substrates or complex feedstocks $[15,53,55,56]$. Similarly, regardless of the initial phylum distribution, we observed the predominance of Firmicutes in all soils and conditions that promoted chain elongation (Figs. 5 and S6). To date, only a few strains from Clostridium and Eubacterium capable of acetate and ethanol chain elongation have been isolated [2]; thus, the ability of microorganisms to grow by chain elongation in most studies with mixed microbial communities is inferred from supporting rather than direct evidence.

Given the featured role of Firmicutes in microbial chain elongation, we further examined the identified genera and species from this phylum (Fig. 6). Miseq-based sequencing of the V4 hyper-variable region of the 16S rRNA gene has been used for species identification but is certainly less accurate than low-throughput methods sequencing the entire 16S rRNA gene [59]. Yet, we note that one identified species common across all soils substantially increased in relative abundance under all chain-elongating conditions: $C$. kluyveri, a strictly chain-elongating bacterium and the model organism for this process. ASVs most similar to $C$. kluyveri (100\% match with C. kluyveri DSM 555) were at detectable abundances $(\leq 0.05 \%)$ in all soils before enrichment at time zero (Fig. 6, t 0). After enrichment, C. kluyveri relative abundance increased to $24-42 \%$ of total sample 

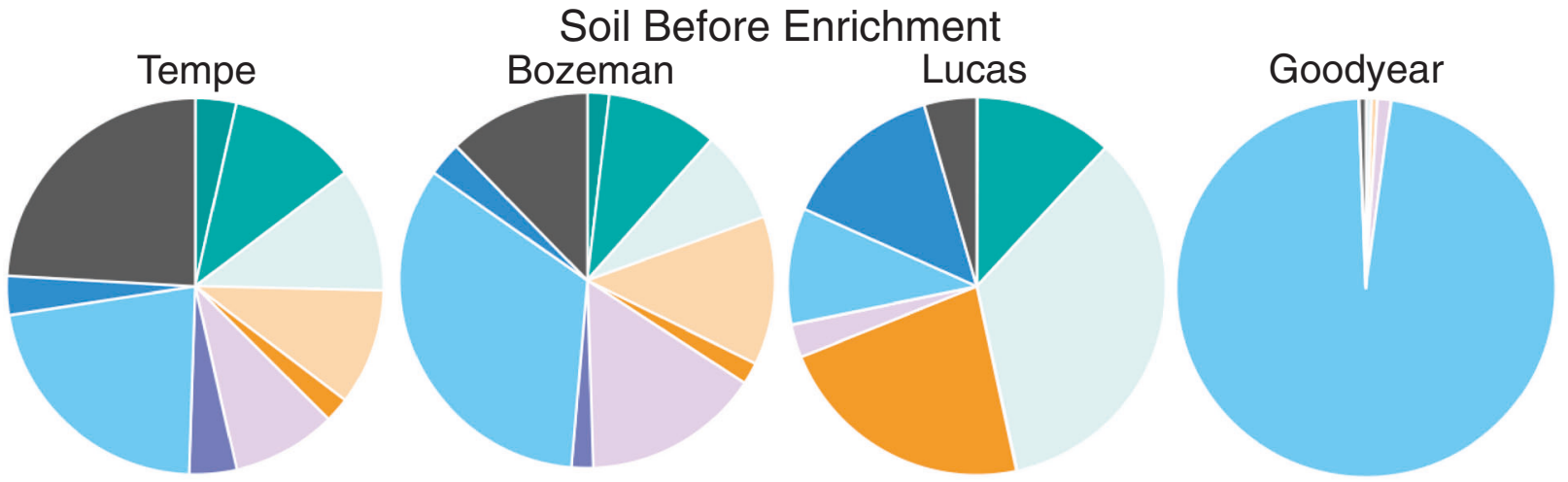

$100 \mathrm{mM}$ Acetate + $100 \mathrm{mM}$ Ethanol Enrichment
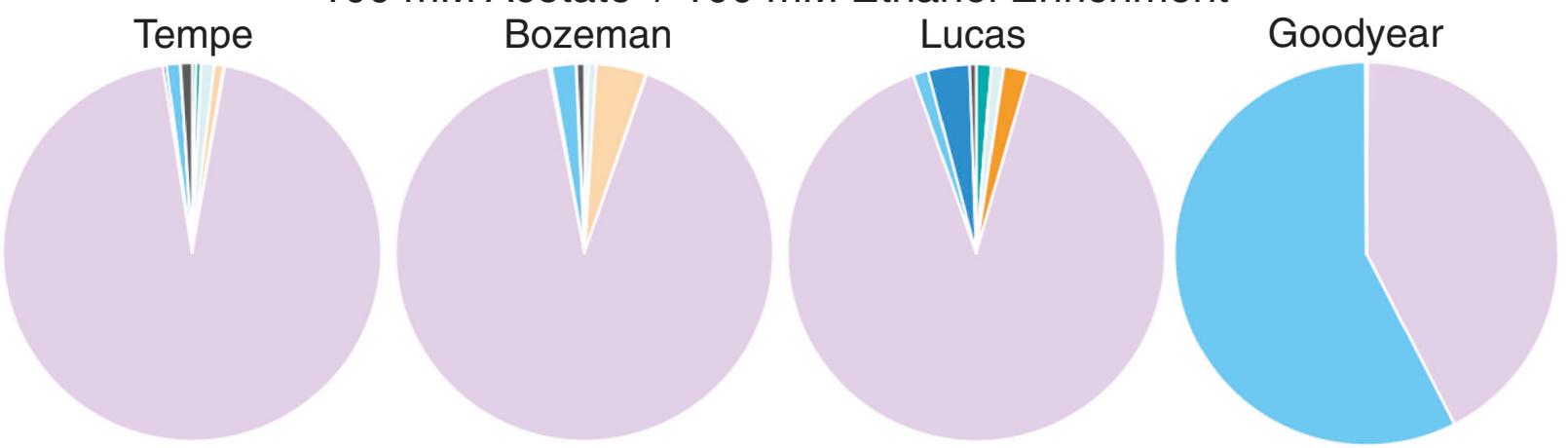

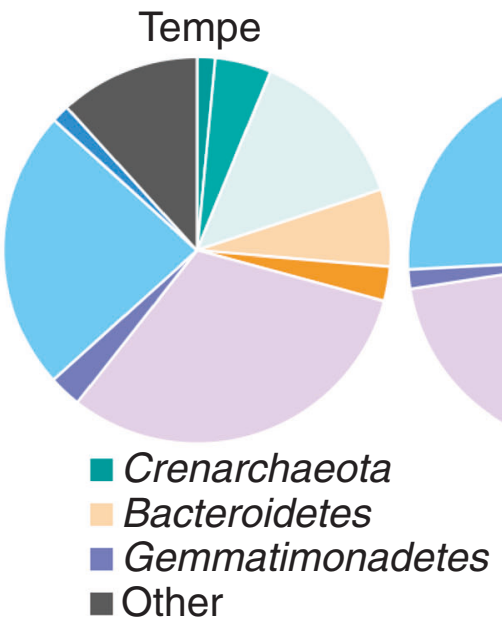

$100 \mathrm{mM}$ Ethanol Enrichment Bozeman

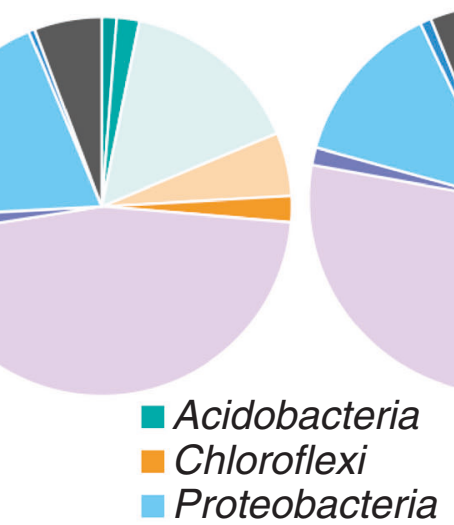

Lucas

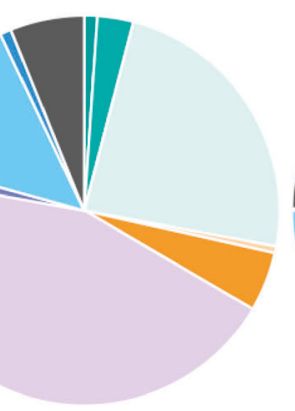

Actinobacteria

Firmicutes

Verrucomicrobia
Fig. 5 The predominance of Firmicutes in chain-elongating soil microbial communities enriched on acetate and ethanol or ethanol.

The data are averages of sequences from duplicate microcosms before enrichment (at time zero) and after enrichment in 4 or 5 semi-batch cycles as specified in Table 2 .

section) and to Oscillospira when using Greengenes database v. 13_8 (data not shown). Sequences from this study most similar to Oscillibacter were $100 \%$ match to uncultured Oscillibacter sp. and $99.3 \%$ match to uncultured Oscillospira. At time zero in all soils, Oscillibacter ASVs were detected at $\leq 0.08 \%$ relative abundance (Fig. 6, t 0 ) and comprised $14-26 \%$ of the total sequences upon acetate and ethanol enrichment in Tempe, Bozeman, and Lucas soils (Fig. 6a-c, AE). In Lucas soil, Oscillibacter ASV was five times more abundant than $C$. kluyveri in the acetate and ethanol condition 
Fig. 6 Diversity of select enriched genera and species in (a) Tempe, (b) Bozeman, (c) Lucas, and (d) Goodyear soil chain-elongating microbial communities. The plotted ASVs show relative abundance from the total sequences obtained in each condition and sampled according to Table 2 . The data are averages of sequences from duplicate microcosms. Labels: $\mathrm{t}$ $0=$ soil before enrichment; NS $=$ No Substrates, $\mathrm{A}=140 \mathrm{mM}$ Acetate; $\mathrm{AE}=100 \mathrm{mM}$ Acetate $+100 \mathrm{mM}$ Ethanol; $\mathrm{E}=100$ $\mathrm{mM}$ Ethanol; $\mathrm{AH}=100 \mathrm{mM}$ Acetate $+\mathrm{H}_{2} ; \mathrm{EH}=100 \mathrm{mM}$ Ethanol $+\mathrm{H}_{2}$.

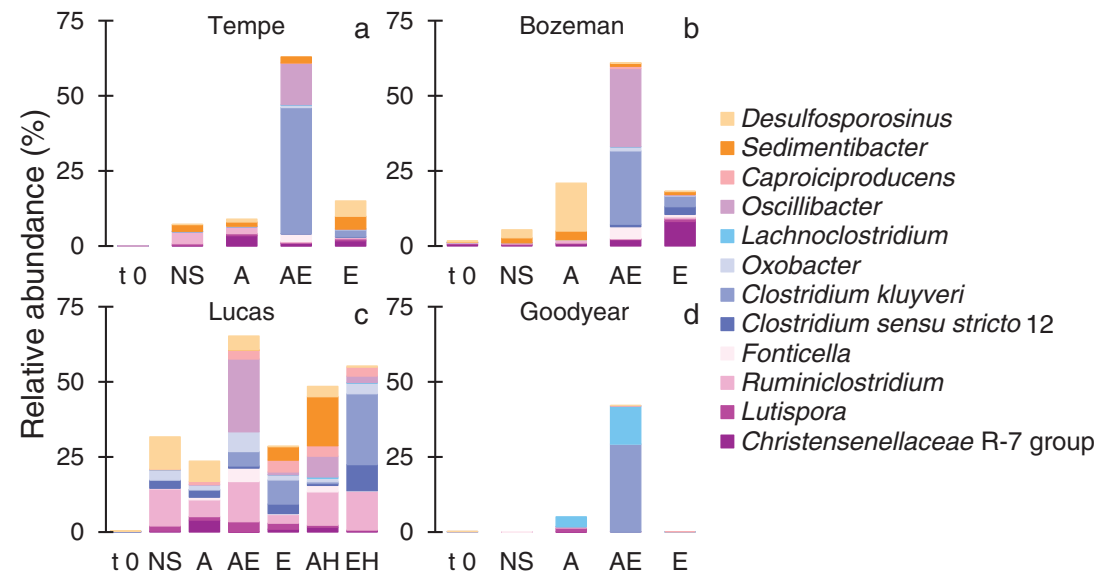

(Fig. 6c, AE). The occurrence of Oscillibacter- or Oscillospira-type microorganisms has rarely been reported or examined in soils [61, 62]. Instead, Oscillibacter and Oscillospira (type strain Oscillospira guilliermondii corrig. Chatton and Pérard 1913) have been of interest as perpetual microbiome members in the rumen of cattle, sheep, and other herbivores, and the human gut [61, 63-65]. Both Oscillibacter ruminantium and Oscillibacter valericigenes grow fermentatively on glucose with butyrate and valerate as main fermentation metabolites, respectively [65, 66]. No isolates of Oscillospira have yet been obtained. Genomic analyses from human gut samples suggest Oscillospira has a fermentative metabolism and produces butyrate, likely utilizing glucuronate, a sugar generated by the human host or obtained from diet containing animal products [67]. Sequences of Oscillibacter and/or Oscillospira at high relative abundance, even greater than $20 \%$ of the total sequences, have been reported in chainelongating bioreactors converting acetate and ethanol to butyrate, hexanoate, and octanoate at $\mathrm{pH} 5.2$ [49, 55], in butyrate- and hexanoate-producing bioreactors fed with synthesis gas [68], or in acetate and ethanol-fed and CO-fed batch cultures $[31,34,56]$. Nonetheless, the metabolism of these microorganisms under chain-elongating conditions remains unknown.

ASVs including Fonticella, Oxobacter, and Ruminoclostridium also substantially enriched relative to time zero under chain-elongating conditions (Fig. 6a-c, AE, E, AH, EH). Species of Fonticella ferment glucose and other sugars to ethanol and acetate [69] while Oxobacter sp. produce butyrate from fermentation of $\mathrm{CO}$ and methoxybenzenoids [70]. In the enrichments from this study, Ruminoclostridium ASV (but also Oscillibacter) was at a higher relative abundance in Lucas soil, which had an initial $\mathrm{pH}$ of 5.7
(Table 1). Lucas soil also maintained a mildly acid $\mathrm{pH}$ during enrichment on acetate and ethanol in semi-batch cycles (Fig. S5). While pH was not the only difference between soils (Table 1), the more acidic $\mathrm{pH}$ possibly explains why $C$. kluyveri was lowest in abundance in Lucas soil enrichment with $100 \mathrm{mM}$ acetate $+100 \mathrm{mM}$ ethanol (Fig. 6c, AE) compared to Tempe, Bozeman, and Goodyear counterparts. Strain K1 of C. kluyveri (DSM 555) isolated from canal mud grows at $\mathrm{pH}$ 6-7.5, with an optimal $\mathrm{pH}$ of 6.8 [1]. Strain 3231B of C. kluyveri isolated from bovine rumen grows in a wider range of $\mathrm{pH}$ (4.9-9.2), although its maximum growth rate is achieved at $\mathrm{pH} 7.6$ [4]. A strain from Ruminococcaceae (CPB6), most similar to the hexanoate-producing Clostridium sp. BS-1 [71], has been isolated and is capable of chain elongation of lactate to butyrate and hexanoate at $\mathrm{pH} 5-6.5$ [72]. Nonetheless, with the exception of $C$. kluyveri, the enriched ASVs from Fig. 6 have not been reported to grow by conversion of acetate and ethanol to $\mathrm{C} 4-\mathrm{C} 8$ carboxylates or by reduction of $\mathrm{C} 4-\mathrm{C} 6$ carboxylates with $\mathrm{H}_{2}$ to $\mathrm{C} 4-\mathrm{C} 6$ alcohols (Figs. 2-3). The soil enrichments also provided conditions for growth of microorganisms with butyrate- and ethanol-consuming capabilities, including Desulfosporosinus [73, 74]. Species of Desulfosporosinus have been co-enriched during bioreactor chain elongation [49, 55] but Desulfosporosinus relative abundance has been negatively correlated with production of more elongated carboxylates.

\section{A potential niche for microbial chain elongation in soils}

We have not yet examined chain elongation in situ nor do we know the extent to which this process occurs under 
natural conditions. Given the artificial conditions in laboratory incubations, the concentrations of microbial chain elongation metabolites observed in our microcosms are not likely to be typical of in situ concentrations. Still, on the basis of this study and our understanding of the process, we expect chain elongation to be triggered during soil events of high release of carboxylates and reduced electron donors (ethanol, $\mathrm{H}_{2}$ ) from animal, plant, and microbial decay. Methane production was purposely inhibited in our experiments to exalt chain-elongation activity. However, methanogenesis can co-occur with chain-elongation [1]. In biotechnology-based research, losses of chain elongation substrates to methane are purposely managed by adding methanogenesis-specific inhibitors such as BES [15] or by selecting bioreactor operating conditions that minimize growth of methanogens (e.g., low $\mathrm{pH}$, high dilution rate) [2]. Conditions that promote chain elongation versus other metabolic processes utilizing simple fermentation products including methanogenesis are probably a combination of several environmental factors. At this point, we can postulate that microbial chain elongation may serve a mechanism to bank electrons and carbon from labile substrates into higher-carbon compounds and to overall delay losses of organic compounds through acetoclastic methanogenesis or mineralization within a soil.

\section{Conclusions}

Chain elongation of acetate and ethanol to butyrate and hexanoate as a growth-dependent metabolism was first described in the soil bacterium, C. kluyveri, more than eight decades ago. Current efforts using complex microbial communities have propelled to fame chain elongation as a biotechnological platform for production of medium-chain carboxylates and other biochemicals. Nonetheless, the possibility of chain elongation as a soil process has remained obscure. This study is the first directed examination on microbial chain elongation as a metabolism involving carbonaceous substrates under anaerobic conditions in soils. We demonstrated that different soil types with various characteristics harbor a readily active potential for chain elongation of acetate and ethanol, typical metabolites from organic compound fermentation. Chain elongation was easily exalted by the presence of acetate and ethanol at concentrations much higher than naturally occurring in soils but also at environmentally relevant concentrations of these substrates. Microorganisms most similar to $C$. kluyveri became highly enriched under chain-elongating conditions. The co-enrichment of several other Firmicutes genera suggests this metabolism may extend to other soil microorganisms. Results from this study support that chain elongation as an energy-conserving pathway should not be overlooked in soil microbial ecology studies. That chain elongation can occur in soils is maybe not surprising but its dynamics in situ is unclear. The extent and role of microbial chain elongation under natural soil conditions is a pertinent research focus in our group.

Acknowledgements We thank Dr. Megan Altizer for procuring Bozeman soil. This study was funded by the National Science Foundation (NSF) under NSF CA No. EEC-1449501. Any opinions, findings, and conclusions or recommendations expressed in this study are those of the authors and do not necessarily reflect those of the NSF.

\section{Compliance with ethical standards}

Conflict of interest The authors declare that they have no conflict of interest.

Publisher's note Springer Nature remains neutral with regard to jurisdictional claims in published maps and institutional affiliations.

Open Access This article is licensed under a Creative Commons Attribution 4.0 International License, which permits use, sharing, adaptation, distribution and reproduction in any medium or format, as long as you give appropriate credit to the original author(s) and the source, provide a link to the Creative Commons license, and indicate if changes were made. The images or other third party material in this article are included in the article's Creative Commons license, unless indicated otherwise in a credit line to the material. If material is not included in the article's Creative Commons license and your intended use is not permitted by statutory regulation or exceeds the permitted use, you will need to obtain permission directly from the copyright holder. To view a copy of this license, visit http://creativecommons. org/licenses/by/4.0/.

\section{References}

1. Barker HA, Taha SM. Clostridium kluyverii, an organism concerned in the formation of caproic acid from ethyl alcohol. J Bacteriol. 1942;43:347-63.

2. Angenent LT, Richter H, Buckel W, Spirito CM, Steinbusch KJJ, Plugge CM, et al. Chain elongation with reactor microbiomes: open-culture biotechnology to produce biochemicals. Environ Sci Technol. 2016;50:2796-810.

3. Béchamp MA. Lettre de m. A. Béchamp a m. Dumas. Ann Chim Phys 1868;4:103-11.

4. Weimer PJ, Stevenson DM. Isolation, characterization, and quantification of Clostridium kluyveri from the bovine rumen. Appl Microbiol Biotechnol. 2012;94:461-6.

5. Kenealy WR, Waselefsky DM. Studies on the substrate range of Clostridium kluyveri - the use of propanol and succinate. Arch Microbiol. 1985;141:187-94.

6. Barker HA, Kamen MD, Bornstein BT. The synthesis of butyric and caproic acids from ethanol and acetic acid by Clostridium kluyveri. Proc Natl Acad Sci USA. 1945;31:373-81.

7. Bornstein BT, Barker HA. The energy metabolism of Clostridium kluyveri and the synthesis of fatty acids. J Biol Chem. 1948;172:659-69.

8. Seedorf H, Fricke WF, Veith B, Bruggemann H, Liesegang H, Strittimatter A, et al. The genome of Clostridium kluyveri, a strict anaerobe with unique metabolic features. Proc Natl Acad Sci USA. 2008;105:2128-33. 
9. Gonzalez-Cabaleiro R, Lema JM, Rodriguez J, Kleerebezem R. Linking thermodynamics and kinetics to assess pathway reversibility in anaerobic bioprocesses. Energy Environ Sci. 2013;6:3780-9.

10. Spirito CM, Richter H, Rabaey K, Stams AJM, Angenent LT. Chain elongation in anaerobic reactor microbiomes to recover resources from waste. Curr Opin Biotechnol. 2014;27:115-22.

11. Rittmann BE \& McCarty PL. Environmental Biotechnology: Principles and Applications. McGraw-Hill Book Education: New York; 2001.

12. Thauer RK, Jungermann K, Henninger H, Wenning J, Decker K. The energy metabolism of Clostridium kluyveri. Eur J Biochem. 1968;4:173-80.

13. Stadtman ER, Barker HA. Fatty acid synthesis by enzyme preparations of Clostridium kluyveri. I. Preparation of cell-free extracts that catalyze the conversion of ethanol and acetate to butyrate and caproate. J Biol Chem. 1949;180:1085-93.

14. Stadtman ER, Barker HA. Fatty acid synthesis by enzyme preparations of Clostridium kluyveri. VI. Reactions of acyl phosphates. J Biol Chem. 1950;184:769-93.

15. Steinbusch KJJ, Hamelers HVM, Plugge CM, Buisman CJN. Biological formation of caproate and caprylate from acetate: fuel and chemical production from low grade biomass. Energy Environ Sci. 2011;4:216-24.

16. Agler MT, Spirito CM, Usack JG, Werner JJ, Angenent LT. Chain elongation with reactor microbiomes: upgrading dilute ethanol to medium-chain carboxylates. Energy Environ Sci. 2012;5:8189-92.

17. Cavalcante WD, Leitao RC, Gehring TA, Angenent LT, Santaella ST. Anaerobic fermentation for $n$-caproic acid production: A review. Process Biochem. 2017;54:106-19.

18. De Groof V, Coma M, Arnot T, Leak DJ, Lanham AB. Medium chain carboxylic acids from complex organic feedstocks by mixed culture fermentation. Molecules 2019;24:398.

19. Schievano A, Sciarria TP, Vanbroekhoven K, De Wever H, Puig $\mathrm{S}$, Andersen SJ, et al. Electro-fermentation - merging electrochemistry with fermentation in industrial applications. Trends Biotechnol. 2016;34:866-78.

20. Jourdin L, Raes SMT, Buisman CJN, Strik D. Critical biofilm growth throughout unmodified carbon felts allows continuous bioelectrochemical chain elongation from $\mathrm{CO}_{2}$ up to caproate at high current density. Front Energy Res. 2018;6:7.

21. Candry P, Huang SL, Carvajal-Arroyo JM, Rabaey K, Ganigue R. Enrichment and characterisation of ethanol chain elongating communities from natural and engineered environments. Sci Rep. 2020;10:1-10.

22. Conrad R. Importance of hydrogenotrophic, aceticlastic and methylotrophic methanogenesis for methane production in terrestrial, aquatic and other anoxic environments: a mini review. Pedosphere 2020;30:25-39.

23. Rui JP, Peng JJ, Lu YH. Succession of bacterial populations during plant residue decomposition in rice field soil. Appl Environ Microbiol. 2009;75:4879-86.

24. Tsutsuki K, Ponnamperuma FN. Behavior of anaerobic decomposition in submerged soils - effect of organic material amendment, soil properties, and temperature. Soil Sci Plant Nutr. 1987;33:13-33.

25. Roy R, Kluber HD, Conrad R. Early initiation of methane production in anoxic rice soil despite the presence of oxidants. FEMS Microbiol Ecol. 1997;24:311-20.

26. Adeleke R, Nwangburuka C, Oboirien B. Origins, roles and fate of organic acids in soils: a review. S Afr J Bot. 2017;108:393-406.

27. Mohana Rangan S, Mouti A, LaPat-Polasko L, Lowry GV, Krajmalnik-Brown R, Delgado A. Synergistic zero-valent iron $\left(\mathrm{Fe}^{0}\right)$ and microbiological trichloroethene and perchlorate reductions are determined by the concentration and speciation of Fe. Environ Sci Technol. 2020;54:14422-31.
28. Delgado AG, Kang D-W, Nelson KG, Fajardo-Williams D, Miceli JF, III, Done HY, et al. Selective enrichment yields robust etheneproducing dechlorinating cultures from microcosms stalled at cisdichloroethene. PLoS ONE. 2014;9:e100654.

29. Delgado AG, Fajardo-Williams D, Popat SC, Torres CI, Krajmalnik-Brown R. Successful operation of continuous reactors at short retention times results in high-density, fast-rate Dehalococcoides dechlorinating cultures. Appl Microbiol Biotechnol. 2014;98:2729-37.

30. Chen TF, Delgado AG, Yavuz BM, Maldonado J, Zuo Y, Kamath $\mathrm{R}$, et al. Interpreting interactions between ozone and residual petroleum hydrocarbons in soil. Environ Sci Technol. 2017;51:506-13.

31. Esquivel-Elizondo S, Miceli J, Torres CI, Krajmalnik-Brown R. Impact of carbon monoxide partial pressures on methanogenesis and medium chain fatty acids production during ethanol fermentation. Biotechnol Bioeng. 2018;115:341-50.

32. Delgado AG, Fajardo-Williams D, Kegerreis KL, Parameswaran P, Krajmalnik-Brown R. Impact of ammonium on syntrophic organohalide-respiring and fermenting microbial communities. mSphere. 2016;1:e00053-16.

33. Delgado AG, Fajardo-Williams D, Bondank E, Esquivel-Elizondo S, Krajmalnik-Brown R. Coupling bioflocculation of Dehalococcoides mccartyi to high-rate reductive dehalogenation of chlorinated ethenes. Environ Sci Technol. 2017;51:11297-307.

34. Esquivel-Elizondo S, Delgado AG, Krajmalnik-Brown R. Evolution of microbial communities growing with carbon monoxide, hydrogen, and carbon dioxide. FEMS Microbiol Ecol. 2017;93: fix076.

35. Xiaoyu Z, Yong T, Cheng L, Xiangzhen L, Na W, Wenjie Z, et al. The synthesis of $n$-caproate from lactate: a new efficient process for medium-chain carboxylates production. Sci Rep. 2015;5:14360.

36. Caporaso JG, Christian LL, William AW, Donna B-L, James H, Noah F, et al. Ultra-high-throughput microbial community analysis on the Illumina HiSeq and MiSeq platforms. ISME J. 2012;6:1621-24.

37. Masella A, Bartram A, Truszkowski J, Brown D, Neufeld J. PANDAseq: paired-end assembler for illumina sequences. BMC Bioinform. 2012;13:31.

38. Bolyen E, Rideout JR, Dillon MR, Bokulich NA, Abnet CC, AlGhalith GA, et al. Reproducible, interactive, scalable and extensible microbiome data science using QIIME 2. Nat Biotechnol. 2019;37:852-57.

39. Callahan BJ, McMurdie PJ, Holmes SP. Exact sequence variants should replace operational taxonomic units in marker-gene data analysis. ISME J. 2017;11:2639-43.

40. Quast C, Pruesse E, Yilmaz P, Gerken J, Schweer T, Yarza P, et al. The SILVA ribosomal RNA gene database project: improved data processing and web-based tools. Nucleic Acids Res. 2013;41:D590-D6.

41. Robeson MS, O'Rourke DR, Kaehler BD, Ziemski M, Dillon MR, Foster JT, et al. RESCRIPt: Reproducible sequence taxonomy reference database management for the masses. bioRxiv. 2020; https://doi.org/10.1101/2020.10.05.326504.

42. Bokulich NA, Kaehler BD, Rideout JR, Dillon M, Bolyen E, Knight R, et al. Optimizing taxonomic classification of markergene amplicon sequences with QIIME 2's q2-feature-classifier plugin. Microbiome. 2018;6:90.

43. Camacho C, Coulouris G, Avagyan V, Ma N, Papadopoulos J, Bealer K, et al. BLAST plus: architecture and applications. BMC Bioinform. 2009;10:1

44. Kusel K, Drake HL. Acetate synthesis in soil from a Bavarian beech forest. Appl Environ Microbiol. 1994;60:1370-3.

45. Kusel K, Drake HL. Effects of environmental parameters on the formation and turnover of acetate by forest soils. Appl Environ Microbiol. 1995;61:3667-75. 
46. Duddleston KN, Kinney MA, Kiene RP, Hines ME. Anaerobic microbial biogeochemistry in a northern bog: Acetate as a dominant metabolic end product. Glob Biogeochem Cycles. 2002;16:11.1-9.

47. Thebrath B, Mayer HP, Conrad R. Bicarbonate-dependent production and methanogenic consumption of acetate in anoxic paddy soil. FEMS Microbiol Ecol. 1992;86:295-302.

48. Delgado AG, Parameswaran P, Fajardo-Williams D, Halden RU, Krajmalnik-Brown R. Role of bicarbonate as a $\mathrm{pH}$ buffer and electron sink in microbial dechlorination of chloroethenes. Microb Cell Fact. 2012;11:128.

49. Kucek LA, Spirito CM, Angenent LT. High n-caprylate productivities and specificities from dilute ethanol and acetate: chain elongation with microbiomes to upgrade products from syngas fermentation. Energy Environ Sci. 2016;9:3482-94.

50. Volker AR, Gogerty DS, Bartholomay C, Hennen-Bierwagen T, Zhu HL, Bobik TA. Fermentative production of short-chain fatty acids in Escherichia coli. Microbiology 2014;160:1513-22.

51. Grootscholten TIM, Steinbusch KJJ, Hamelers HVM, Buisman CJN. Chain elongation of acetate and ethanol in an upflow anaerobic filter for high rate MCFA production. Bioresour Technol. 2013;135:440-5.

52. Reddy MV, Mohan SV, Chang YC. Medium-chain fatty acids (MCFA) production through anaerobic fermentation using Clostridium kluyveri: effect of ethanol and acetate. Appl Biochem Biotechnol. 2018;185:594-605.

53. Scarborough MJ, Lawson CE, Hamilton JJ, Donohue TJ, Noguera DR. Metatranscriptomic and thermodynamic insights into medium-chain fatty acid production using an anaerobic microbiome. mSystems 2018;3:6.

54. Bao S, Wang QY, Zhang PY, Zhang Q, Wu Y, Li F, et al. Effect of acid/ethanol ratio on medium chain carboxylate production with different VFAs as the electron acceptor: insight into carbon balance and microbial community. Energies 2019;12:3720.

55. Spirito CM, Marzilli AM, Angenent LT. Higher substrate ratios of ethanol to acetate steered chain elongation toward $n$-caprylate in a bioreactor with product extraction. Environ Sci Technol. 2018;52:13438-47.

56. Coma M, Vilchez-Vargas R, Roume H, Jauregui R, Pieper DH, Rabaey K. Product diversity linked to substrate usage in chain elongation by mixed-culture fermentation. Environ Sci Technol. 2016;50:6467-76.

57. Janssen PH. Identifying the dominant soil bacterial taxa in libraries of 16S rRNA and 16S rRNA genes. Appl Environ Microbiol. 2006;72:1719-28.

58. Spain AM, Krumholz LR, Elshahed MS. Abundance, composition, diversity and novelty of soil Proteobacteria. ISME J 2009;3:992-1000

59. Johnson JS, Spakowicz DJ, Hong BY, Petersen LM, Demkowicz P, Chen L, et al. Evaluation of $16 \mathrm{~S}$ rRNA gene sequencing for species and strain-level microbiome analysis. Nat Commun. 2019;10:5029.

60. Hollister EB, Forrest AK, Wilkinson HH, Ebbole DJ, Malfatti SA, Tringe SG, et al. Structure and dynamics of the microbial communities underlying the carboxylate platform for biofuel production. Appl Microbiol Biotechnol. 2010;88:389-99.

61. Mackie RI, Aminov RI, Hu WP, Klieve AV, Ouwerkerk D, Sundset MA, et al. Ecology of uncultivated Oscillospira species in the rumen of cattle, sheep, and reindeer as assessed by microscopy and molecular approaches. Appl Environ Microbiol. 2003;69:6808-15.

62. Ye TR, Cai HY, Liu X, Jiang HL. Dominance of Oscillospira and Bacteroides in the bacterial community associated with the degradation of high-concentration dimethyl sulfide under ironreducing condition. Ann Microbiol. 2016;66:1199-206.

63. Konikoff T, Gophna U. Oscillospira: a central, enigmatic component of the human gut microbiota. Trends Microbiol. 2016;24:523-4.

64. Clarke RTJ. Niche in pasture-fed ruminants for the large rumen bacteria Oscillospira, Lampropedia, and Quin's and Eadie's ovals. Appl Environ Microbiol. 1979;37:654-7.

65. Lee GH, Rhee MS, Chang DH, Lee J, Kim S, Yoon MH, et al. Oscillibacter ruminantium sp nov., isolated from the rumen of Korean native cattle. Int J Syst Evol Microbiol. 2013;63:1942-6.

66. Iino T, Mori K, Tanaka K, Suzuki KI, Harayama S. Oscillibacter valericigenes gen. nov., sp nov., a valerate-producing anaerobic bacterium isolated from the alimentary canal of a Japanese corbicula clam. Int J Syst Evol Microbiol. 2007;57:1840-5.

67. Gophna U, Konikoff T, Nielsen HB. Oscillospira and related bacteria - From metagenomic species to metabolic features. Environ Microbiol. 2017;19:835-41.

68. Wang H-J, Dai K, Wang Y-Q, Wang H-F, Zhang F, Zeng RJ. Mixed culture fermentation of synthesis gas in the microfiltration and ultrafiltration hollow-fiber membrane biofilm reactors. Bioresour Technol. 2018;267:650-6.

69. Fraj B, Ben Hania W, Postec A, Hamdi M, Ollivier B, Fardeau ML. Fonticella tunisiensis gen. nov., sp nov., isolated from a hot spring. Int J Syst Evol Microbiol. 2013;63:1947-50.

70. Collins MD, Lawson PA, Willems A, Cordoba JJ, Fernandezgarayzabal J, Garcia P, et al. The phylogeny of the genus Clostridium - Proposal of 5 new genera and 11 new species combinations. Int J Syst Bacteriol. 1994;44:812-26.

71. BS Jeon, Kim BC, Um Y, et al. BI. Production of hexanoic acid from D-galactitol by a newly isolated Clostridium sp. BS-1. Appl Microbiol Biotechnol. 2010;88:1161-7.

72. Zhu XY, Zhou Y, Wang Y, Wu TT, Li XZ, Li DP, et al. Production of high-concentration $n$-caproic acid from lactate through fermentation using a newly isolated Ruminococcaceae bacterium CPB6. Biotechnol Biofuels. 2017;10:102.

73. Robertson WJ, Bowman JP, Franzmann PD, Mee BJ. Desulfosporosinus meridiei sp nov., a spore-forming sulfate-reducing bacterium isolated from gasolene-contaminated groundwater. Int J Syst Evol Microbiol. 2001;51:133-40.

74. Lee YJ, Romanek CS, Wiegel J. Desulfosporosinus youngiae sp nov., a spore-forming, sulfate-reducing bacterium isolated from a constructed wetland treating acid mine drainage. Int J Syst Evol Microbiol. 2009;59:2743-6. 